\title{
Manutenção de colônias Apis mellifera no período de escassez de alimento
}

\section{Maintenance of Apis mellifera colonies in the period of food scarcity}

\author{
Renata Valéria Regis de Sousa Gomes ${ }^{1}$; Lidiany Barros Rocha ${ }^{2}$; Maria Elaine de Miranda ${ }^{2}$ Ednilson \\ Nogueira de Lima Filho ; João Gustavo Souza Sales de Albuquerque ${ }^{2}$; Daiana Silva Sombra ${ }^{3}$ \\ ${ }^{1}$ Doutora em Ciência Animal, Departamento de Zootecnia da Universidade Federal Rural de Pernambuco, Recife, Pernambuco (81) 3320-6572, \\ renatav_sousa@hotmail.com; ${ }^{2}$ Graduando(a) em Zootecnia, Departamento de Zootecnia da Universidade Federal Rural de Pernambuco, Recife, \\ rochalidiany@gmail.com; elainemiranda02@hotmail.com; ednilsonnogueira@hotmail.com; joao_gustavo_ssa@hotmail.com; ${ }^{3}$ Doutora em Ciência Animal, \\ Universidade Federal Rural do Semi-Árido, Mossoró, Rio Grande do Norte; daianasombra@ hotmail.com
}

\section{A R T I G O}

Recebido: $27 / 10 / 2018$

Aprovado: 26/06/2019

\section{Palavras-chave:}

Apicultura

Alimentação artificial

Conservação de colônias

Key words:

Beekeeping

Artificial feeding

Colony conservation.

\section{R E S U M O}

O objetivo dessa pesquisa foi avaliar a manutenção de colônias de abelhas africanizada (Apis mellifera L.) alimentadas artificialmente no período de entressafra. Foram utilizadas 22 colônias de abelhas africanizadas abrigadas em colmeias Langstroth e fornecido semanalmente alimento energético e proteico em alimentadores individuais. $\mathrm{O}$ alimento energético foi composto de açúcar e água na concentração 1:1. Para alimentação proteica foram formuladas três rações: tratamento $2(5.8 \%$ de soja, $11.8 \%$ de trigo e $11.8 \%$ de milho); tratamento 3 (9.8\% de soja, $9.8 \%$ de trigo e $9.8 \%$ de milho); e tratamento 4 (14.7\% de soja, $7.35 \%$ de trigo e $7.35 \%$ de milho) e utilizado o beebread como tratamento controle. As colônias foram revisadas quinzenalmente e avaliado o consumo das rações e o desenvolvimento das colônias pelos quadros com crias. Verificou-se que não houve enxameação por abandono durante o período do experimento. Observou-se que o tratamento controle e o tratamento 2 foram as dietas com maior consumo, apresentando o tratamento controle (beebread) diferença estatística significativa em relação ao tratamento $3 \mathrm{e}$ tratamento 4 , e não diferiu estatisticamente do tratamento 2 . O tratamento 3 e tratamento 4 apresentavam as maiores quantidades de soja na composição. Verificou-se que não houve diferença estatística significativa na média de quadros com crias entre os tratamentos. A alimentação artificial no período de entressafra proporciona a manutenção das colônias de abelhas Apis mellifera.

\section{A B S T R A C T}

The aim of this research was to evaluate colony maintenance of Africanized bees (Apis mellifera L.), artificially fed in off-season. Twenty-two Africanized bee colonies housed in Langstroth hives were used and fed weekly on individual feeders with energetic (syrup) and protein (slurry ration) feed. The energy feed was composed of sugar and water at a concentration of $1: 1$. For protein feeding, three diets were formulated: treatment 2 (5.8\% soybean, $11.8 \%$ wheat and $11.8 \%$ corn); treatment $3(9.8 \%$ soybean, $9.8 \%$ wheat and $9.8 \%$ corn); and treatment 4 (14.7\% soybean, $7.35 \%$ wheat and $7.35 \%$ corn) and beebread was used as a control treatment. The colonies were reviewed fortnightly. Was rated feed intake and the development of colonies by comb brood. It was found that there was no abandonment swarm during the experiment period. Control and treatment 2 were the most consumed diets, with the control treatment (beebread) showing a statistically significant difference from treatment 3 and treatment 4 , and did not differ statistically from treatment 2 . Treatment 3 and treatment 4 had the highest amounts of soy in the composition. It was verified that there was no statistically significant difference in the average of comb brood between the treatments. Artificial feeding in the off-season provides maintenance of Apis mellifera bee colonies.

\author{
Revista Verde \\ ISSN 1981-8203 \\ Pombal, Paraíba, Brasil
}

v. 14, n.3, jul.-set, p.458-463, 2019

doi: 10.18378/rvads.v14i3.6486 


\section{INTRODUÇÃO}

A apicultura tem se consolidado como uma importante fonte de geração de emprego e renda, especialmente para o pequeno produtor que está inserido no contexto da agricultura familiar na região Nordeste do Brasil (GONÇALVES et al., 2010). Um dos grandes desafios para o desenvolvimento sustentável da apicultura nessa região é a implantação de tecnologias que considerem as variáveis climáticas, por essa região ser caracterizada pela existência de duas estações no ano, a chuvosa (inverno) e a seca (verão).

É fundamental que os criadores de abelhas tenham conhecimento da época que a disponibilidade de néctar e pólen se torna escassa na natureza, considerando que a apicultura é uma atividade vulnerável aos fatores climáticos adversos. Nas regiões semiáridas, a falta de chuvas devido ao longo período de estiagem que teve início em 2012, provocou uma queda de mais de $50 \%$ na produção apícola Nordestina, ocasionando prejuízos e grandes perdas de colônias de abelhas, colocando a atividade em níveis críticos (VIDAL, 2017). Nas regiões de zona da mata, o período das chuvas contínuas é considerado crítico para o desenvolvimento das colônias de abelhas, que além de ser a época de escassez de néctar e pólen na natureza, apresentam condições climáticas desfavoráveis para as atividades de voos das abelhas campeiras (GOMES et al., 2017).

A escassez de néctar e pólen combinado com os estressores climáticos interferem diretamente na manutenção e desenvolvimento das colônias, por esses impedirem que as exigências nutricionais que as abelhas necessitam sejam satisfeitas. A condição de fome afeta diretamente a saúde, reprodução e longevidade das abelhas (BRODSCHNEIDER; CRAILSHEIM, 2010). A coleta de pólen, néctar e água está intrinsicamente relacionada com a quantidade de alimento no campo e, quando a disponibilidade desses recursos não corresponde às necessidades da colônia, ocasiona uma brusca redução no tamanho da população, aumenta a susceptibilidade a doenças, levando muitas vezes a extinção do enxame (DI PASQUALE et al., 2013; LI et al., 2012).

A deficiência de alimento além de afetar a fisiologia das abelhas e a produtividade das colônias, pode ocasionar prejuízos como a enxameação por abandono. As perdas de colônias na época de ausência de floradas, e quando as reservas de alimento na colônia são insuficientes, é um fenômeno sazonal, que pode ser mitigado com a disponibilidade de alimento artificial, evitando assim, que as colônias não encontrem fontes de alimentos e deixem a área com a colônia completa (MORAIS et al., 2013). Sendo necessário considerar alguns atributos como a palatabilidade e o valor nutricional da dieta (DIAS et al., 2018), além dos custos e disponibilidade no mercado.

Com isso, objetivou-se avaliar a manutenção de colônias de abelhas Apis mellifera alimentadas artificialmente no período de entressafra.

\section{MATERIAL E MÉTODOS}

A pesquisa foi realizada no apiário experimental do Departamento de Zootecnia da Universidade Federal Rural de Pernambuco, localizado na mesorregião fisiográfica do litoral e zona da mata, no município de Recife. Nessa região, o período crítico de disponibilidade de alimento na natureza para as abelhas é entre os meses de maio a agosto, período que compreende as mais altas médias de índice pluviométrico e umidade, em torno de $725 \mathrm{~mm}$ e $75.6 \%$ respectivamente, com temperatura média de $24^{\circ} \mathrm{C}$ (APAC, 2015).

Para instalação do experimento foram utilizadas 22 colônias de abelhas do polihíbrido africanizada (Apis mellifera L.), abrigadas em colmeias modelo Langstroth, para as quais foram fornecidas em alimentadores individuais alimentação energética (xarope) e proteica (ração em pasta).

$\mathrm{O}$ alimento energético fornecido foi composto de açúcar e água na concentração $1: 1$, sendo ofertado $500 \mathrm{~mL}$ semanal para cada colmeia por treze semanas, a partir do mês de maio. Para alimentação proteica foram formuladas três rações com diferentes concentrações de farelo de milho, farelo de soja e farelo de trigo, que foram moídos e peneirados até ficar uma farinha bem fina. Para o tratamento controle (T0) foi utilizado beebread ou "pão de abelha" que foi colhido das colmeias do próprio apiário no período de floração e mantido nos favos. A dieta proteica foi administrada por nove semanas durante os meses de julho e agosto, simultânea à líquida, sendo fornecido $100 \mathrm{~g}$ para cada colmeia semanalmente (Tabela 1, Figura 1A, Figura 1B).

As rações e o beebread foram conservados em freezer, sendo a quantidade utilizada em cada semana descongelada, pesada e ofertada em temperatura ambiente. As rações (tratamentos T2, T3 e T4) foram servidas em pratos descartáveis e o beebread no favo cortado (Figura 1A, Figura 1B), dispostos sobre os quadros do ninho Ad Libitum. Semanalmente foram recolhidas as sobras, e o consumo de cada tratamento foi obtido pela diferença entre o peso inicial $(100 \mathrm{~g})$ e o peso final (sobras) para cada colmeia/tratamento.

Tabela 1. Quantidade de ingredientes utilizados na composição das rações dos tratamentos $\mathrm{T} 2, \mathrm{~T} 3$ e $\mathrm{T} 4$, especificando as quantidades utilizadas da farinha de milho, soja, trigo e açúcar em gramas $(\mathrm{g})$ e de mel em mililitro $(\mathrm{mL})$, e seu respectivo percentual $(\%)$.

\begin{tabular}{|c|c|c|c|c|c|}
\hline \multirow[t]{2}{*}{ Tratamentos } & \multicolumn{4}{|c|}{$\begin{array}{c}\text { Composição da ração em g } \\
\%\end{array}$} & \multirow{2}{*}{$\begin{array}{c}\mathrm{mL} \\
\% \\
\mathrm{Mel}\end{array}$} \\
\hline & Milho & Soja & Trigo & Açúcar & \\
\hline \multirow{2}{*}{$\mathrm{T} 2$} & 600 & 300 & 600 & 3000 & 600 \\
\hline & 11.8 & 5.8 & 11.8 & 58.8 & 11.8 \\
\hline \multirow{2}{*}{ T3 } & 500 & 500 & 500 & 3000 & 600 \\
\hline & 9.8 & 9.8 & 9.8 & 58.8 & 11.8 \\
\hline \multirow{2}{*}{$\mathrm{T} 4$} & 375 & 750 & 375 & 3000 & 600 \\
\hline & 7.35 & 14.7 & 7.35 & 58.8 & 11.8 \\
\hline
\end{tabular}

Figura 1. A: Favo com Beebread; B: Amostra da ração utilizada nos tratamentos.

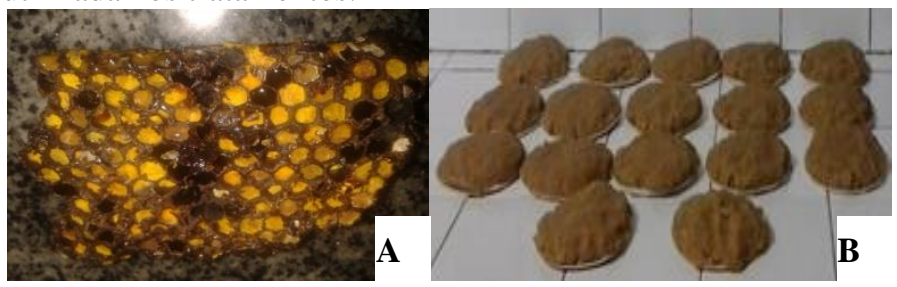


As colmeias foram revisadas quinzenalmente e registrado o número de quadros com crias antes do início do fornecimento das rações e durante as revisões. Para o acompanhamento do desenvolvimento das colônias, foi utilizando o método adaptado de Al-Tikrity et al. (1971), onde cada quadro com cria foi introduzido dentro de um suporte de madeira, tendo na parte anterior uma rede de arame dividida em 50 quadrantes de áreas idênticas, permitindo visualizar e avaliar nos quadros a área ocupada por ovos, crias abertas, crias operculadas, néctar, mel operculado, pólen e favo vazio por cada quadrante.

Todas as despesas financeiras com a produção das dietas, os custos por colmeia para cada $100 \mathrm{~g}$ da ração e $500 \mathrm{~mL}$ do xarope, que foi a quantidade fornecida semanalmente para cada colônia, estão descritas na tabela 2 .

Tabela 2. Custos em Reais ( $R \$$ ) referentes aos ingredientes para produção da ração proteica e para $100 \mathrm{~g}$ de cada tratamento e $500 \mathrm{~mL}$ de xarope (alimento energético) fornecido semanalmente por colônia.

\begin{tabular}{|c|c|c|c|}
\hline \multirow{2}{*}{ Ingredientes } & \multicolumn{3}{|c|}{$\begin{array}{l}\text { Custo em } \mathrm{R} \$ \text { para produção da ração } \\
\text { de cada tratamento }\end{array}$} \\
\hline & $\mathrm{T} 2$ & T3 & T4 \\
\hline Farelo de soja & 0.72 & 1.20 & 1.80 \\
\hline Farelo de milho & 0.96 & 0.80 & 0.60 \\
\hline Farelo de trigo & 0.60 & 0.50 & 0.38 \\
\hline Açúcar & 11.76 & 11.76 & 11.76 \\
\hline Mel & 4.80 & 4.80 & 4.80 \\
\hline \multirow[t]{2}{*}{ Total } & 18.84 & 19.06 & 19.34 \\
\hline & \multicolumn{3}{|c|}{ Custo semanal em $\mathrm{R}$ \$ por colônia } \\
\hline Dieta & $\mathrm{T} 2$ & T3 & T4 \\
\hline $100 \mathrm{~g}$ dieta proteica & 0.3768 & 0.3812 & 0.3868 \\
\hline 500mL xarope & 0.59 & 0.59 & 0.59 \\
\hline Total & 0.9668 & 0.9712 & 0.9768 \\
\hline
\end{tabular}

Semanalmente foram avaliadas as características organolépticas (cor, odor e textura) das rações e registrado o tempo de conservação. Também foi realizada a análise bromatológica das dietas quanto à matéria seca (MS), matéria mineral $(\mathrm{MM})$, proteína bruta $(\mathrm{PB})$, fibra solúvel em detergente neutro (FDN), fibra solúvel em detergente ácido (FDA) e gordura (EE), conforme metodologias descritas por Detmann et al. (2012).

Os resultados obtidos com o consumo das rações e com o desenvolvimento das colônias pelos quadros com crias, foram avaliados por meio da estatística descritiva e pela análise de variância em torno do delineamento inteiramente casualizado (DIC), considerando o nível de significância de 5\%, por meio do modelo apresentado na equação 1 .

$$
\mathrm{y}_{\mathrm{ij}}=\mathrm{m}+\mathrm{t}_{\mathrm{i}}+\mathrm{e}_{\mathrm{ij}}
$$

Em que: $\mathrm{y}_{\mathrm{ij}}=$ valor observado na unidade experimental que recebeu o tratamento $i$, repetição $j ; m=$ efeito geral da média; $t_{i}$ $=$ efeito do tratamento $\mathrm{i} ; \mathrm{e}_{\mathrm{ij}}=$ erro aleatório (resíduo).
Para a comparação das médias utilizou-se o teste de Tukey ao nível de $5 \%$ de probabilidade, mediante o programa estatístico R Core Team (2018).

\section{RESULTADOS E DISCUSSÃO}

Com as revisões quinzenais das 22 colônias avaliadas, verificou-se que não houve enxameação por abandono durante o período experimental.

Observou-se que a média de consumo das rações por tratamento/colmeia durante o experimento foi: $\mathrm{T} 1=91.78 \mathrm{~g}$ $\pm 8.75 ; \quad \mathrm{T} 2=72.90 \mathrm{~g} \pm 14 ; \quad \mathrm{T} 3=66.82 \mathrm{~g} \pm 16.78 ;$ e $\mathrm{T} 4=65.60 \mathrm{~g}$ \pm 21.33 , consumindo as abelhas em maior quantidade o tratamento $\mathrm{T} 1$ e em menor quantidade a ração do tratamento $\mathrm{T} 4$ (Figura 2). $\mathrm{O}$ consumo diário foi: $\mathrm{T} 1=13.11 \mathrm{~g} / \mathrm{dia}$; $\mathrm{T} 2=10.41 \mathrm{~g} / \mathrm{dia} ; \mathrm{T} 3=9.54 \mathrm{~g} / \mathrm{dia} ; \mathrm{T} 4=9.37 \mathrm{~g} / \mathrm{dia}$. O consumo do tratamento $\mathrm{T} 1$ (beebread) apresentou diferença estatística significativa em relação aos tratamentos $\mathrm{T} 3$ e $\mathrm{T} 4$ que apresentavam as maiores quantidades de soja na composição, e não diferiu estatisticamente do tratamento $\mathrm{T} 2$.

$\mathrm{O}$ alimento energético (xarope) foi totalmente consumido e observou-se que as abelhas estocavam e operculavam o xarope nos favos do ninho.

Figura 2. Consumo (g) total e diário de beebread e das rações com concentrações de soja, trigo e milho por Apis mellifera.

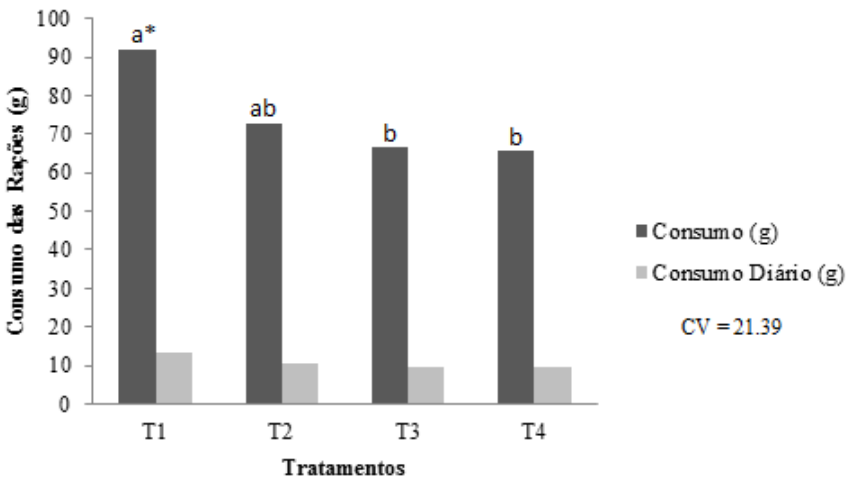

Legenda: *Letras diferentes indicam diferença estatística significativa entre os tratamentos de acordo com o teste Tukey ao nível de $5 \%$ de probabilidade. Tratamentos: T1(beebread ou "pão de abelha"); T2 (5.8\% de soja, $11.8 \%$ de trigo e $11.8 \%$ de milho); T3 (9.8\% de soja, $9.8 \%$ de trigo e $9.8 \%$ de milho); e T4 (14.7\% de soja, $7.35 \%$ de trigo e $7.35 \%$ de milho).

De acordo com Lima et al., (2017) uma alimentação eficiente para as abelhas apresenta efeito benéfico no desempenho das colônias, podendo assim ser utilizada como uma ferramenta para manter os enxames em períodos de escassez alimentar. Sendo importante considerar que é inviável o uso de alimento artificial para as abelhas no período de disponibilidade de alimento na natureza, por o alimento natural ser capaz de suprir as exigências nutricionais da colônia (OLIVEIRA, 2016).

O beebread foi a dieta mais consumida durante todo o período experimental, seguida do tratamento T2 (Figura 3). Observou-se que nos 21 primeiros dias de administração da dieta proteica foram os que se obtiveram as maiores médias de 
consumo em todos os tratamentos $\quad(\mathrm{T} 1=98.27 \mathrm{~g} \quad \pm 2.83$; $\mathrm{T} 2=81.17 \mathrm{~g} \pm 15.50 ; \mathrm{T} 3=71.71 \mathrm{~g} \pm 19.10 ;$ e $\mathrm{T} 4=83.12 \mathrm{~g} \pm 16.34)$ (Figura 3). Havendo diminuição no consumo entre o $42^{\circ}$ dia $(\mathrm{T} 1=95.50 \mathrm{~g} \pm 2.61 ; \mathrm{T} 2=77.67 \mathrm{~g} \pm 7.31 ; \mathrm{T} 3=78.10 \mathrm{~g} \pm 4.62 ; \mathrm{e}$ $\mathrm{T} 4=67.97 \mathrm{~g} \pm 15.17)$ e $63^{\circ}$ dia $(\mathrm{T} 1=81.57 \mathrm{~g} \pm 7.14 ; \mathrm{T} 2=59.86 \mathrm{~g}$ \pm 9.96 ; $\mathrm{T} 3=50.66 \mathrm{~g} \pm 11.08$; e $\mathrm{T} 4=45.71 \mathrm{~g} \pm 16.19$ ), o que pode ser justificado pela redução do volume de chuvas e início da floração de algumas espécies vegetais na região, o que possibilitou a atividade de vôo das abelhas campeiras e a oferta de néctar e pólen na natureza.

Figura 3. Consumo (g) de beebread e das rações com concentrações de soja, trigo e milho por Apis mellifera aos 21, 42 e 63 dias.

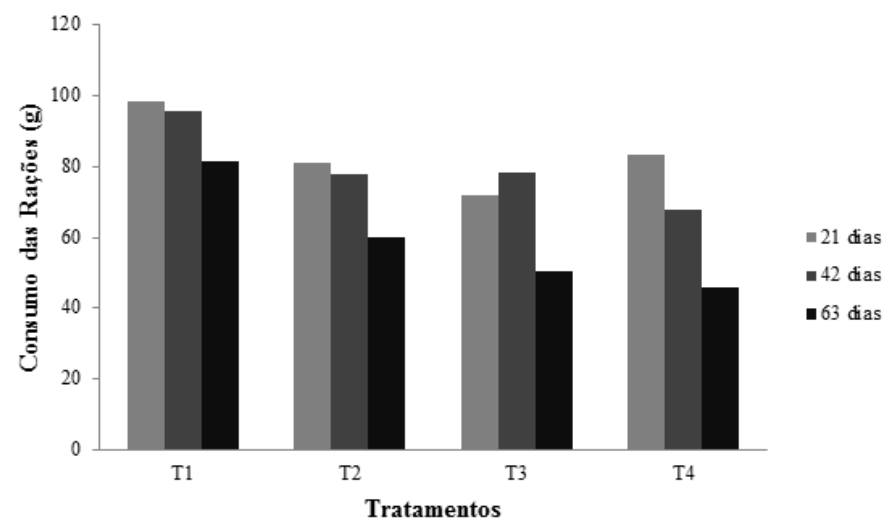

Legenda: Tratamentos: T1(beebread ou "pão de abelha"); T2 (5.8\% de soja, $11.8 \%$ de trigo e $11.8 \%$ de milho); T3 (9.8\% de soja, $9.8 \%$ de trigo e $9.8 \%$ de milho); e T4 (14.7\% de soja, $7.35 \%$ de trigo e $7.35 \%$ de milho).

A importância do fornecimento de alimento para as abelhas no período de entressafra é corroborada pela ausência de enxameação por abandono durante o período experimental. A falta de manejo alimentar no período de escassez na natureza ocasiona perdas que chegam a $80 \%$ das colônias, como foi observado no Estado de Pernambuco, que de um total de 300.000 colmeias com abelhas no ano de 2012, no início de 2013, 240.000 estavam vazias devido à escassez de alimento na natureza, ocasionado pelo longo período de estiagem que assolou o Nordeste brasileiro (VIDAL, 2013).

$\mathrm{O}$ fornecimento de alimento energético e proteico para as abelhas no período de entressafra é uma prática de manejo que deve ser implementada pelos produtores em seus apiários, para além da manutenção das colônias, proporcionar a conservação, desenvolvimento e aumento populacional, evitando assim perdas de colônias pelo comportamento de enxameação por abandono que ocorre anualmente na época de carência de alimento na natureza e de condições ambientais adversas (PEREIRA et al., 2014).

O preparo e fornecimento de alimentação na época de escassez na natureza é uma prática simples, considerando que a mistura de água e açúcar (sacarose) é suficiente para proporcionar a energia necessária às colônias. Bem como o alimento proteico, para o qual se deve avaliar a palatabilidade, facilidade de preparo, disponibilidade e baixo custo, além da validação de ingredientes de espécies vegetais nativas, que não apresentem toxicidade e, possam ser considerados na formulação de ração proteica para abelhas, como o feno de leucena, o feno de mandioca, farelo de babaçu, e a farinha de vagem de algaroba fornecidas in natura (PEREIRA, F. et al., 2007; COELHO et al., 2008).

É necessário ressaltar que a manutenção de colônias de abelhas no período de entressafra vai além do fornecimento de alimento proteico e energético, fazendo-se necessário considerar a importância da oferta de sombreamento e água, especialmente na região Nordeste do Brasil. As altas temperaturas aliadas à intensa radiação solar vêm sendo, também, um fator limitante para o desenvolvimento e manutenção das colônias de abelhas. A falta de sombreamento no apiário ocasiona um superaquecimento dentro das colmeias, e consequentemente um aumento na temperatura corporal das abelhas, o que pode comprometer a sobrevivência da colônia (DOMINGOS et al., 2018; SANTOS et al., 2017). A água é considerada um elemento vital para as abelhas, utilizada tanto nos processos fisiológicos de digestão e metabolismo, como para manter a estabilidade térmica da colônia, tanto em nível de colônia, quando as abelhas a utilizam no controle da temperatura e umidade relativa dentro da colmeia, como a nível individual, pois em climas quentes, a água pode ser utilizada pelas abelhas para o arrefecimento corporal (DOMINGOS et al., 2018)

No desenvolvimento das colônias, verificou-se que a média geral do número de quadros com crias por tratamento variou entre 3.5 a 4.4, apresentando os tratamentos as seguintes médias de quadros com crias: $\mathrm{T} 1=4.4 \pm 0.9 ; \mathrm{T} 2=4.2 \pm 0.4$; T3=3.6 \pm 1.3 ; e T4=3.5 \pm 0.9 , não havendo diferença estatística significativa entre os tratamentos (Figura 4).

Figura 4. Desenvolvimento das colônias de Apis mellifera por quantidade de quadros com crias.

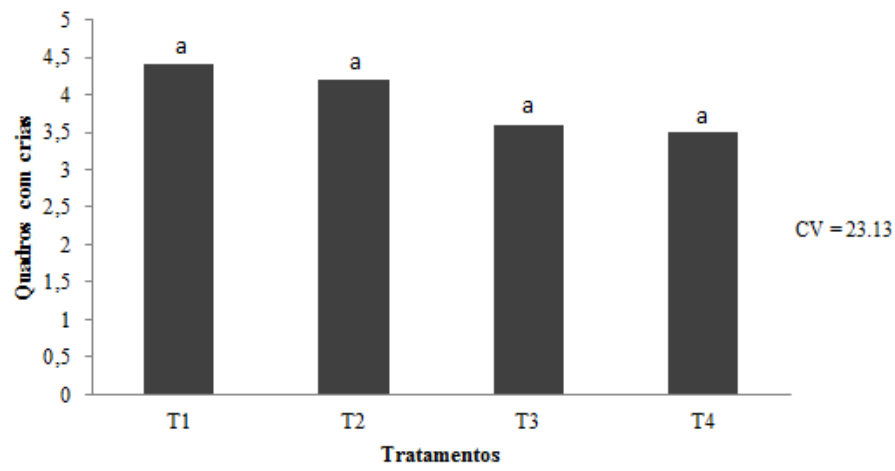

Legenda: Médias seguidas da mesma letra não diferem entre si (Tukey 5\%). Tratamentos: T1(beebread ou "pão de abelha"); T2 (5.8\% de soja, 11.8\% de trigo e $11.8 \%$ de milho); T3 (9.8\% de soja, $9.8 \%$ de trigo e $9.8 \%$ de milho); e T4 (14.7\% de soja, $7.35 \%$ de trigo e $7.35 \%$ de milho).

Comparando-se o número de quadros com crias das colônias antes e após a administração da dieta proteica, verificou-se que não houve diferença estatística significativa entre os tratamentos (Figura 5).

Apesar das dietas utilizadas não terem proporcionado diferenças estatísticas significativas quanto ao número de quadros com crias entre os tratamentos, a utilização de dietas proteicas e energéticas é uma prática essencial para manutenção da atividade apícola, considerando-se que foi evitada a perda de 
enxames no período de entressafra. O que proporciona ao criador o controle da qualidade das abelhas, considerando que sempre que se perdem colônias, o repovoamento dos apiários é realizado por meio de capturas de enxames na natureza, sem ter o conhecimento da procedência da colônia e da idade e qualidade genética da rainha (GOMES et al., 2017).

Figura 5. Número de quadros com crias das colmeias de Apis mellifera antes e após o fornecimento do beebread e das rações com concentrações de soja, trigo e milho.

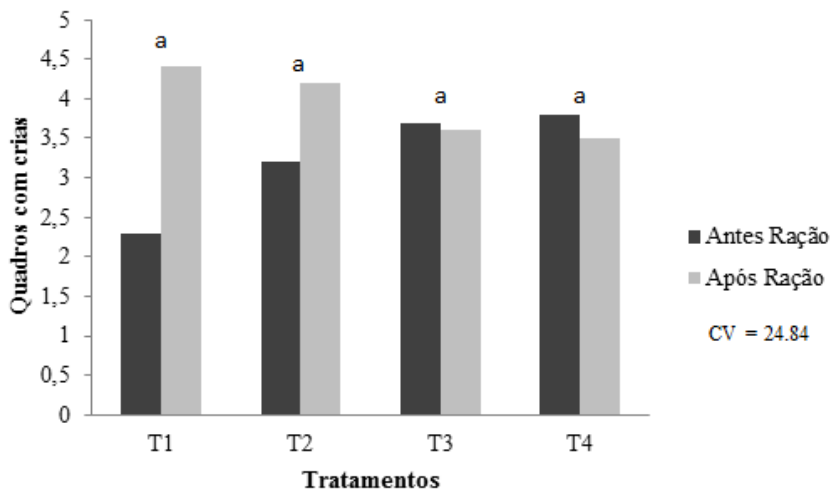

Legenda: Médias seguidas da mesma letra não diferem entre si (Tukey 5\%). Tratamentos: T1(beebread ou "pão de abelha"); T2 (5.8\% de soja, $11.8 \%$ de trigo e $11.8 \%$ de milho); T3 (9.8\% de soja, $9.8 \%$ de trigo e $9.8 \%$ de milho); e T4 (14.7\% de soja, $7.35 \%$ de trigo e $7.35 \%$ de milho).

O fornecimento de dieta energética (xarope), que é considerada alimentação de mantença, logo no início do período de escassez de alimento na natureza, e a proteica pelo menos 45 dias antes do início da florada, auxilia as colônias a reduzirem o enfraquecimento, não necessitando de uma recuperação maior das colônias para mantê-la populosa, garantindo maior produção na safra seguinte (PEGORARO et al., 2013).

Quanto aos custos para produção das dietas e a aceitação pelo consumo das abelhas, verificou-se que o tratamento T2 foi $\mathrm{o}$ que apresentou melhor custo $\mathrm{x}$ benefício, em relação aos tratamentos T3 e T4, considerando-se que o custo total do tratamento $\mathrm{T} 2$ foi de $\mathrm{R} \$ 11.06$ (onze reais e seis centavos) por colônia, para todo o período experimental (Tabela 2, Figura 2). Sendo R\$ 7.67 (sete reais e sessenta e sete centavos) de alimento energético e R\$ 3.39 (três reais e trinta e nove centavos) de alimento proteico, para o período de fornecimento de 13 e 9 semanas respectivamente. $O$ custo total por colmeia para o apicultor é baixo, considerando o tempo de administração. Sugerindo-se maior viabilidade financeira a coleta e armazenamento de favos com beebread (pão de abelha) no período de safra, época que ocorre grande entrada de pólen na colmeia, não havendo assim, custos com a produção desse alimento.

O tempo de conservação das características organolépticas (cor, odor e textura) das rações e do beebread foram de sete meses. Após esse período verificou-se que as rações em pasta passaram a apresentar uma textura ressequida e o beebread alteração no odor.

A análise bromatológica das dietas com suas respectivas composição nutricional (Tabela 3) demonstraram que o teor de
PB (proteína bruta) do beebread (T1) foi de $22.22 \%$. Os tratamentos T2 $(4.06 \%)$, T3 $(7.16 \%)$, T4 $(8.93 \%)$ apresentaram valores de proteína bruta (PB) inferiores em relação ao beebread, demonstrando esses resultados que o fornecimento de alimento (energético e proteico), independente do teor proteico, garante a manutenção das colônias no período de entressafra, considerando que a composição nutricional do pólen apícola é influenciada pelas diferentes características florísticas (MODRO et al., 2007).

Tabela 3. Análise bromatológica das dietas testadas em porcentagem $(\%)$.

\begin{tabular}{ccccc}
\hline Análises & Beebread & T2 & T3 & T4 \\
\hline MS & 70.16 & 80.70 & 82.38 & 80.51 \\
MM & 2.49 & 1.10 & 0.88 & 1.36 \\
EE & 1.87 & 0.50 & 1.54 & 1.21 \\
FDN & 6.51 & 6.20 & 6.83 & 6.05 \\
FDA & 0.47 & 1.30 & 1.50 & 2.03 \\
PB & 22.22 & 4.06 & 7.16 & 8.93 \\
\hline \\
Legenda: matéria seca (MS), matéria mineral (MM), gordura (EE), fibra \\
solúvel em detergente neutro (FDN), fibra solúvel em detergente ácido (FDA) \\
eproteína bruta (PB).
\end{tabular}

Os resultados das análises da matéria seca (MS), matéria mineral (MM), gordura (EE), fibra solúvel em detergente neutro (FDN) e fibra solúvel em detergente ácido (FDA), apresentaram valores bem próximos em todos os tratamentos, exceto o (EE) do T2 e o (FDA) do beebread que apresentaram valor menor em relação aos demais tratamentos. A importância da análise bromatológica da ração e do beebread, se dá pelo fato das abelhas terem necessidade de consumir alimentos que contenham, além da proteína, teores de lipídeos, vitaminas e minerais para seu pleno crescimento, desenvolvimento e reprodução (STANDIFER et al., 1977). O alto teor de (MS) das rações e do beebread (Tabela 3) está relacionado com a capacidade de consumo do alimento, que de acordo com Andriguetto (2002) é onde estão os nutrientes (carboidratos, proteínas, minerais), são constituídos por água (umidade) e seu teor pode variar de $5 \%$ a $95 \%$.

\section{CONCLUSÕES}

A alimentação artificial no período de entressafra proporciona a manutenção das colônias de abelhas Apis mellifera.

\section{REFERÊNCIAS}

APAC, AGÊNCIA PERNAMBUCANA DE ÁGUAS E CLIMA. Meteorologia. Disponível em: <http://www.apac.pe.gov.br/meteorologia/estacoes-doano.php> Acesso em 24 julho 2019.

ANDRIGUETTO, J. M. Nutrição animal: alimentação animal. São Paulo, Nobel, v. 2, 2002.

BRODSCHNEIDER, R.; CRAILSHEIM, K. Nutrition and health in honey bees. Apidologie, v.41, p.278-294, 2010. $\underline{10.1051 / a p i d o / 2010012}$ 
COELHO, M. S.; SILVA, J. H. V.; OLIVEIRA, E. R. A.; ARAÚJO, J. A.; LIMA, M. R. Alimentos convencionais e alternativos para abelhas. Revista Caatinga, v.21, n.1, p.01-09, 2008.

DETMANN, E.; SOUZA, M. A.; VALADARES FILHO, S. C. Métodos para análise de alimentos - INCT - Ciência Animal. Visconde do Rio Branco: Suprema, 2012. 214p.

DI PASQUALE, G.; SALIGNON, M.; LE CONTE, Y.; BELZUNCES, L. O.; DECOURTYE, A.; KRETZSCHMAR, A.; SUCHAIL, S.; BRUNET, J.L.; ALAUX, C. Influence of Pollen Nutrition on Honey Bee Health: Do Pollen Quality and Diversity Matter?. PlosOne, v.8, n.8, p. 1-13, 2013. 10.1371/journal.pone.0072016.

DIAS, J. M. V. A.; MORAIS, M. M.; FRANCOY, T. M.; PEREIRA, R. A.; TURCATTO, A. P.; DE JONG, D. Fermentation of a pollen substitute diet with beebread microorganisms increases diet consumption and hemolymph protein levels of honey bees (Hymenoptera, Apidae). Sociobiology, v.65, n.4, p.760-765, 2018. $\underline{10.13102 / \text { sociobiology.v65i4.3293 }}$

DOMINGOS, H. G. T.; SOMBRA, D. S.; SANTOS, R. G.; GRAMACHO, K. P.; GONÇALVES, L. S. Surface temperature and heat transfer between body regions of africanized honeybees (Apis mellifera L.) in hives under sun and shade conditions in the Northeastern Semi-arid Region of Brazil. Journal of Agricultural Science and Technology, v.8, p.28-35, 2018. 10.17265/2161-6256/2018.01.004

GOMES, R. V. R. S.; MIRANDA, M. E.; GOMES, E. N.; SOMBRA, D. S.; SILVA, J. B. A. Produção e qualidade de mel na zona da mata de Pernambuco. Enciclopédia Bioesfera, v.14, n.26, p.540-549, 2017. doi: 10.18677/EnciBio_2017B52.

GONÇALVES, L. S.; DE JONG, D.; GRAMACHO, K. P. A expansão da apicultura e da tecnologia apícola no Nordeste brasileiro com especial destaque para o Rio Grande do Norte. Mensagem Doce, v. 3, p. 7-15, 2010.

LI, C.; XU, B.; WANG, Y.; FENG, Q.; YANG, W. Effects of dietary crude protein levels on development, antioxidant status, and total midgut protease activity of honey bee (Apis mellifera ligustica). Apidologie, v. 43, n. 5, p. 576-586, 2012. 10.1007/s13592-012-0126-0.

LIMA, M. V.; SOARES, K. O.; EVANGELISTARODRIGUES, A. Complexo enzimático na alimentação artificial de abelhas africanizadas. Arch. Zootec. v.66, n.255, p.415-420, 2017.

MODRO, A. F. H.; MESSAGE, D.; LUZ, C. F. P.; MEIRA NETO, J. A. A. Composição e qualidade de pólen apícola coletado em Minas Gerais. Pesq. Agropec. Bras., v.42, n.8, p.1057-1065, 2007. 10.1590/S0100-204X2007000800001.
MORAIS, M. M.; TURCATTO, A. P.; FRANCOY, T. M.; GONÇALVES, L. S.; CAPPELARI, F. A.; DE JONG, D. Evaluation of inexpensive pollen substitute diets through quantification of haemolymph proteins. Journal of Apicultural Research, v.52, n.3, p.119-121, 2013. 10.3896/IBRA.1.52.3.01.

OLIVEIRA, J. W. S. Efeito da suplementação proteica sobre características morfométricas de rainhas de abelhas africanizadas (Apis mellifera L.). 2016. 39f. Dissertação (Mestrado em Zootecnia) Universidade Federal de Sergipe, São Cristovão, 2016.

PEGORARO, A.; NUNES, F. L.; PEREIRA, F. F.; TEIXEIRA, R. A.; KRUGER, E.; SERMANN, K. C. Perdas de colônias de Apis mellifera L. no inverno suplementadas com alimentação artificial com pólen e favos de mel. Revista Agrarian, v.6, n.19, p.67-74, 2013.

PEREIRA, D. S.; HERNÁNDEZ, M. L.; ANDRADE, A. B. A.; SOUSA, J. S.; MARACAJÁ, P. B. Alimentação de abelhas Apis mellifera L. (Africanizadas) no período de estiagem, no Semiárido Nordestino, Brasil. Revista Verde de Agroecologia e Desenvolvimento Sustentável, v.9, n.5, p. 117-119, 2014. $\underline{10.18378 / \text { rvads.v9i5.3421 }}$

PEREIRA, F. M.; FREITAS, B. M.; VIEIRA NETO, J. M.; LOPES, M. T. R.; BARBOSA, A. L.; CAMARGO, R. C. R.; RIBEIRO, V. Q.; ROCHA, R. S. Efeito tóxico de alimentos alternativos para abelhas Apis mellifera. Ciência Rural, v.37, n.2, p.533-538, 2007.

R CORE TEAM R A language and environment for statistical computing. R Foundation for Statistical Computing, Vienna, Austria. 2018. Disponível em: <https://www.R-project.org/>. Acesso em 24 julho 2019.

SANTOS, R. G.; DOMINGOS, H. G. T.; GRAMACHO, K. P.; GONÇALVES, L. S. Sombreamento de colmeias de abelhas africanizadas no Semiárido Brasileiro. Revista Verde de Agroecologia e Desenvolvimento Sustentável, v.12, n. 5, 2017. 10.18378/rvads.v12i5.5407.

STANDIFER, L. N.; MOELLER, F. E.; KAUFFELD, N. M.; HERBERT JR., E. W.; SHIMANUKI, H. Supplemental feeding of honey bee colonies. United States Departament of Agriculture. Agriculture Information Bulletin, n. 413, p. 1-8, 1977.

VIDAL, M. F. Efeitos da seca de 2012 sobre a apicultura nordestina. Informe Rural Etene, ano 7, n.2, p.1-5, 2013.

VIDAL, M. F. Desempenho da apicultura Nordestina em anos de estiagem. Caderno Setorial Etene, ano 2, n.11, p.2-10, 2017. 